Western University

Scholarship@Western

Medical Biophysics Publications

Medical Biophysics Department

$1-2015$

Hippocampal volume, early cognitive decline and gait variability: Which association?

Olivier Beauchet

Cyrille P Launay

Cédric Annweiler

Western University, cannweil@uwo.ca

Gilles Allali

Follow this and additional works at: https://ir.lib.uwo.ca/biophysicspub

Part of the Medical Biophysics Commons

Citation of this paper:

Beauchet, Olivier; Launay, Cyrille P; Annweiler, Cédric; and Allali, Gilles, "Hippocampal volume, early cognitive decline and gait variability: Which association?" (2015). Medical Biophysics Publications. 26.

https://ir.lib.uwo.ca/biophysicspub/26 


\title{
Hippocampal volume, early cognitive decline and gait variability: Which association?
}

\author{
Olivier Beauchet ${ }^{\mathrm{a}, *}$, Cyrille P. Launay ${ }^{\mathrm{a}}$, Cédric Annweiler ${ }^{\mathrm{a}, \mathrm{b}}$, Gilles Allali ${ }^{\mathrm{c}, \mathrm{d}}$ \\ a Department of Neuroscience, Division of Geriatric Medicine, Angers University Hospital, University Memory Clinic of Angers, UPRES EA 4638, University of Angers, UNAM, Angers, France \\ ${ }^{\mathrm{b}}$ Center for Functional Metabolic Mapping, Robarts Research Institute, Department of Medical Biophysics, Schulich School of Medicine and Dentistry, the University of Western Ontario, London, \\ Ontario, Canada \\ ${ }^{\mathrm{c}}$ Department of Neurology, Geneva University Hospital and University of Geneva, Switzerland \\ d Department of Neurology, Division of Cognitive \& Motor Aging, Albert Einstein College of Medicine, Yeshiva University, Bronx, NY, USA
}

\section{A R T I C L E I N F O}

\section{Article history:}

Received 25 July 2014

Received in revised form 31 October 2014

Accepted 4 November 2014

Available online 6 November 2014

Section Editor: Christian Humpel

\section{Keywords:}

Gait

Hippocampus

Magnetic resonance imaging

Motor control

Older adults

Mild cognitive impairment

\begin{abstract}
A B S T R A C T
Background: In contrast to its prominent function in cognition, the involvement of the hippocampus in gait control is still a matter of debate. The present study aimed to examine the association of the hippocampal volume with mean values and coefficients of variation $(\mathrm{CoV})$ of spatio-temporal gait parameters among cognitively healthy individuals $(\mathrm{CHI})$ and patients with mild cognitive impairment $(\mathrm{MCI})$.

Methods: A total of 90 individuals ( $47 \mathrm{CHI}$ with a mean age of $69.7 \pm 3.6$ years and $48.9 \%$ women, and $43 \mathrm{MCI}$ individuals with a mean age of $70.2 \pm 3.7$ years and $62.8 \%$ women) were included in this cross-sectional study. The hippocampal volume was quantified from a three-dimensional $\mathrm{T}_{1}$-weighted MRI using semiautomated software. Mean values and $\mathrm{CoV}$ of stride time, swing time and stride width were measured at selfselected pace with a $10 \mathrm{~m}$ electronic portable walkway (GAITRite $\left.{ }^{\circledR}\right)$. Age, gender, body mass index, number of drugs daily taken, Mini-Mental State Examination (MMSE) score, history of falls, walking speed and white matter signal-intensity abnormality scoring with Manolio scale were used as covariates.

Results: Patients with MCI had a lower MMSE score $(\mathrm{P}<0.001)$, a higher $\mathrm{CoV}$ of stride time $(\mathrm{P}=0.013)$ and a lower hippocampal volume $(\mathrm{P}=0.007)$ compared with $\mathrm{CHI}$. Multiple linear regression models showed that $\mathrm{CoV}$ of stride time was specifically associated with higher hippocampal volume among $\mathrm{CHI}(\mathrm{P}<0.05)$ but not among patients with MCI $(\mathrm{P}>0.650)$.

Conclusions: Our findings revealed a positive association between a greater (i.e., better morphological structure) hippocampal volume and a greater (i.e., worse performance) stride time variability among $\mathrm{CHI}$, but not among $\mathrm{MCI}$ individuals.
\end{abstract}

(c) 2014 Elsevier Inc. All rights reserved.

\section{Introduction}

The hippocampus is a key human brain region involved in memorization and locomotion (Seidler et al., 2010; Scherder et al., 2007; Lithfous et al., 2013). Atrophy of the hippocampus has been related to memory disorders and diagnosis of mild cognitive impairment (MCI), which is a transitional state between normal cognitive functioning and dementia (Fellgiebel \& Yakushev, 2011; Leal \& Yassa, 2013; Albert et al., 2011). In Alzheimer's disease (AD), the hippocampus constitutes one of the first brain areas affected by neurodegenerative lesions, causing its atrophy, explaining why hippocampal abnormality is considered as a biomarker of Alzheimer (Albert et al., 2011; Dubois et al., 2014). In contrast to its prominent function in cognition, the involvement of the

\footnotetext{
* Corresponding author at: Department of Neuroscience, Division of Geriatric Medicine, Angers University Hospital, 49933 Angers Cedex 9, France.

E-mail address: olbeauchet@chu-angers.fr (O. Beauchet).
}

hippocampus in gait control, and thus in the maintenance of gait stability, is still a matter of debate. For instance and when considering the hippocampal volume, Zimmermann et al. reported a non-significant association between hippocampal volume and stride-to-stride variability, whereas other studies showed a significant negative association (Zimmerman et al., 2009; Shimada et al., 2013; Rosso et al., 2014; Annweiler et al., 2014).

Divergence could be due to the studied population and/or the type of spatio-temporal gait parameters examined. Negative results have been found in the unique study that examined both cognitive healthy individuals ( $\mathrm{CHI}$ ) and patients with $\mathrm{MCI}$, whereas all other studies focused on CHI (Zimmerman et al., 2009; Shimada et al., 2013; Rosso et al., 2014; Annweiler et al., 2014). In terms of control of gait, gait variability has been identified as an appropriate biomarker for the measure of the cortical control of gait in normal aging and in patients with dementia (Beauchet et al., 2009a, 2014; Montero-Odasso et al., 2012). Furthermore, higher (i.e., worse) stride time variability (STV) was specifically associated with lower cognitive performance in episodic memory 
and executive function among older community-dwellers without dementia (Beauchet et al., 2014). This finding was confirmed by a meta-analysis underscoring that higher STV was related to both $\mathrm{MCI}$ and dementia (Beauchet et al., 2014). In addition, in terms of gait instability, it has been underscored that the general assumption that variability and stability are negatively correlated cannot be a universal rule. Indeed, higher and lower variability have been reported in younger and older $\mathrm{CHI}$ with safe gait, this apparent discrepancy being related to the type of gait parameters examined (Beauchet et al., 2009a, 2014; Montero-Odasso et al., 2012). In particular, lower STV, intermediate swing time variability and higher stride width variability have been associated with safe gait in $\mathrm{CHI}$ (Beauchet et al., 2009a). These results were explained by the fact that these spatio-temporal gait parameters reflect different components of gait control (Beauchet et al., 2009a; Montero-Odasso et al., 2012; Beauchet et al., 2013). STV is a marker of the control of rhythmic stepping mechanism, whereas stride width reflects the dynamic postural control, and swing time combines the two previous components of gait control (Beauchet et al., 2009a; Montero-Odasso et al., 2012; Beauchet et al., 2013).

To better understand the relationship between hippocampal volume, early cognitive decline and gait variability, there is a need to examine the association of hippocampal volume with specific gait parameters reflecting the different components of gait control such as stride time, swing time and stride width among $\mathrm{CHI}$ and patients with $\mathrm{MCI}$. Because it has been shown that patients with MCI present independently a greater gait variability and a lower hippocampal volume compared to CHI (Albert et al., 2011; Dubois et al., 2014; Zimmerman et al., 2009; Shimada et al., 2013; Rosso et al., 2014; Annweiler et al., 2014), we hypothesized that higher gait variability would be stronger associated with lower hippocampal volume in $\mathrm{MCI}$ individuals compared to $\mathrm{CHI}$. We had the opportunity to test this hypothesis in the "Gait and Alzheimer Interactions Tracking" (GAIT) study, which is a crosssectional study aiming to compare gait characteristics of $\mathrm{CHI}$ and patients with $\mathrm{MCl}$ and $\mathrm{AD}$, and to examine the association between gait characteristics and brain morphology. The aim of the present study was to examine the association of the hippocampal volume with stride time, swing time and stride width variability among $\mathrm{CHI}$ and individuals with any form of $\mathrm{MCI}$ (i.e., amnestic or non-amnestic, and single or multiple domains).

\section{Material and methods}

\subsection{Participants}

Between November 2009 and July 2010, 90 individuals (47 CHI and $43 \mathrm{MCl}$ individuals) were recruited in the GAIT study, which is an ongoing study. The study procedure has been previously described in detail (Beauchet et al., 2013). Briefly, all participants were referred for the evaluation of memory complaints at the memory clinic of Angers University Hospital, France. The eligibility criteria were: age 65 years and over, ambulatory, an adequate understanding of French, and no acute medical illness in the past month. For the present analysis, exclusion criteria were: dementia, extrapyramidal rigidity of the upper limbs, neurological and psychiatric diseases other than cognitive impairment, severe medical conditions affecting walking, inability to walk 15 min unassisted, or the presence of depressive symptoms defined by a 4item Geriatric Depression Scale score above 1 (Shah et al., 1997). All participants received a full standardized medical examination, a neuropsychological and gait assessment, and MRI of the brain. The number of drugs taken daily, and the use of psychoactive drugs (i.e., benzodiazepines, antidepressants, or neuroleptics), antidiabetic drugs, antihypertensive drugs and lipid-lowering drugs were recorded. Antidiabetic, antihypertensive and lipid-lowering drugs were combined into a single category of cardiovascular drugs.

\subsection{Neuropsychological assessment}

A neuropsychological assessment was performed on each participant during a face-to-face examination by a neuropsychologist. The following standardized tests were used to probe several aspects of cognitive function: MMSE (Folstein et al., 1975), Frontal Assessment Battery (FAB) (Dubois et al., 2000), Alzheimer's Disease Assessment Scale-Cognitive subscale (ADAS-cog) (Rosen et al., 1984), Trail Making Test (TMT) parts A and B (Brown et al., 1958), French version of the Free and Cued Selective Reminding Test (Grober et al., 1988; Van der Linden et al., 2004), and Instrumental Activities of Daily Living scale (IADL) (Pérès et al., 2006). The diagnosis of $\mathrm{MCl}$ was made during multidisciplinary meetings involving geriatricians, neurologists, and neuropsychologists of Angers University Memory Clinic, and was based on the aforementioned neuropsychological tests, physical examination findings, blood tests, and MRI of the brain. MCI was diagnosed according to the criteria detailed by Dubois et al. (2010). Participants with any form of $\mathrm{MCI}$, amnesic or non-amnesic and affecting single or multiple domains, were included in this study. Participants who had normal neuropsychological and functional performances were considered as cognitively healthy.

\subsection{Gait assessment}

Spatio-temporal gait parameters including stride time, swing time and stride width were recorded at self-selected usual pace using a computerized walkway with embedded pressure sensors (GAITRite ${ }^{\circledR}$ Gold walkway, $972 \mathrm{~cm}$ long, active electronic surface area $792 \times 610 \mathrm{~cm}$, total 29,952 pressure sensors, scanning frequency $60 \mathrm{~Hz}$, CIR System, Havertown, PA) according to the European guidelines for spatiotemporal gait analysis in older adults (Beauchet et al., 2011; Kressig \& Beauchet, 2006). Briefly, the participants were asked to walk at their usual self-selected walking speed in a quiet, well-lit corridor wearing their own footwear. To avoid acceleration and deceleration effects, participants started walking $1 \mathrm{~m}$ before reaching the electronic walkway and completed their walk $1 \mathrm{~m}$ beyond it. For each parameter, mean value and coefficient of variation $(\mathrm{CoV}=($ standard deviation $/$ mean $) \times 100)$ were recorded.

\subsection{Hippocampal volume}

Imaging of the brain was performed with a 1.5-Tesla MRI scanner (Magnetom Avanto, Siemens Medical Solutions, Erlangen, Germany) using a standard MRI protocol (Dubois et al., 2009) including 3D $\mathrm{T}_{1}$ weighted magnetization prepared rapid acquisition gradient echo (MP-RAGE) axial images (acquisition matrix $=256 \times 256 \times 144$, FOV $=240 \mathrm{~mm} \times 240 \mathrm{~mm} \times 187 \mathrm{~mm}, \mathrm{TE} / \mathrm{TR} / \mathrm{TI}=4.07 \mathrm{~ms} / 2170 \mathrm{~ms} /$ $1100 \mathrm{~ms}$ ), and fluid-attenuated inversion recovery (FLAIR) axial images (acquisition matrix $=256 \times 192, \mathrm{FOV}=240 \mathrm{~mm} \times 180 \mathrm{~mm}$, slice thickness $=5 \mathrm{~mm}$, slice gap $=0.5 \mathrm{~mm}$, 30 slices, TE $/ \mathrm{TR} / \mathrm{TI}=122 \mathrm{~ms} /$ $9000 \mathrm{~ms} / 2500 \mathrm{~ms}$ ).

The volumetric $3 \mathrm{D} \mathrm{T}_{1}$-weighted images were segmented using the FreeSurfer software package (version 5.1.0; 33) to calculate the hippocampal volume. FreeSurfer is a set of tools that automatically segments and labels brain structures based on established processing steps; the technical specifications of these procedures have been described previously (Fischl et al., 2002). Briefly, this processing included removal of non-brain tissue using a hybrid watershed/surface deformation procedure (Jovicich et al., 2006), automated Talairach transformation, segmentation of the sub-cortical white matter and deep gray matter structures (Segonne et al., 2004; Fischl et al., 2004), tessellation of the gray matter/white matter boundary, automated topology correction (Jovicich et al., 2006; Fischl et al., 2001), registration to a spherical atlas (Fischl et al., 1999a), parcellation of the cerebral cortex into units based on gyral and sulcal structures (Segonne et al., 2004; Fischl et al., 1999b), surface inflation and creation of surface-based data (Desikan 
et al., 2006). The procedures for the measurement of cortical volume have been validated against histological analysis (Dale et al., 1999) and manual measurements (Rosas et al., 2002; Kuperberg et al., 2003). Freesurfer morphometric procedures have demonstrated good test-retest reliability across scanner manufacturers and across field strengths (Han et al., 2006). Two endpoints were used in the analysis: the absolute hippocampal volume expressed in $\mathrm{mm}^{3}$, and the ratio of absolute hippocampal volume $\left(\mathrm{mm}^{3}\right) /$ total brain volume $\left(\mathrm{mm}^{3}\right)$.

\subsection{Covariables}

Gait variability may be influenced by several clinical variables, which are potential confounders when examining its relationship with the hippocampal volume (Annweiler et al., 2014; Beauchet et al., 2009a, 2014; Montero-Odasso et al., 2012; Beauchet et al., 2011, 2013; Kressig \& Beauchet, 2006). The main potential confounders (i.e., age, gender, body mass index, number of drugs daily taken, history of falls in the past year) were recorded using a standardized comprehensive geriatric assessment (Beauchet et al., 2013). Walking speed may also influence gait variability, lower walking speed being associated with higher gait variability (Beauchet et al., 2009b) explaining why it was used as a covariable in the analysis. In our study, walking speed was measured at self-selected usual pace with the GAITRite ${ }^{\circledR}$ system. Lastly, it has been reported that white matter hyperintensities (WMHs) is associated with higher gait variability (Rosano et al., 2007). Therefore, the total extent of white matter signal-intensity abnormality was measured using the semiquantitative visual rating scale devised by Manolio and colleagues (Manolio et al., 1994), with a score ranging from 0 (i.e., best) to 9 (i.e., worst). The inter-rater agreement of this scale is fair (Cohen $\kappa=0.59$ ) (Kapeller et al., 2003). A Manolio score $>3$ was considered as significant WMHs and was used as covariable in the analysis.

\subsection{Ethics}

Participants in the study were included after having given their written informed consent for research. The study was conducted in accordance with the ethical standards set forth in the Helsinki Declaration (1983). The entire study protocol was approved by Angers local Ethical Committee, France.

\subsection{Statistics}

The participants' characteristics were summarized using means and standard deviations or frequencies and percentages, as appropriate. Normality of data distribution was checked using a skewness-kurtosis test. As the number of observations was $>40$ for each group, no transformations were applied to the variables of interest. For the current analysis, participants were classified into 2 groups, as follows: $\mathrm{CHI}$ and patients with $\mathrm{MCl}$. First, between-group comparisons were performed using unpaired $t$-test, Mann-Whitney or Chi-square test, as appropriate. Second, univariate and multiple linear regression analyses were performed to examine the association between spatiotemporal parameters (dependent variables) and the hippocampal volume (independent variables) adjusted on the participants' characteristics. P-values less than 0.05 were considered as statistically significant. All statistics were performed using SPSS (version 15.0; SPSS, Inc., Chicago, IL).

\section{Results}

Clinical and hippocampal characteristics are presented in Table 1. Patients with $\mathrm{MCI}$ had a lower MMSE score $(\mathrm{P}<0.001$ ), a higher $\mathrm{CoV}$ of stride time $(\mathrm{P}=0.013)$ and a lower hippocampal volume $(P=0.007)$. There was no significant difference for the other participant's characteristics. Fig. 1 shows T1-weighted MRI images of hippocampus of three characteristic participants: two cognitively healthy individuals (one with a low hippocampal volume $\left(2913 \mathrm{~mm}^{3}\right.$ ) and a low $\mathrm{CoV}$ of stride time (1.3\%) (a) and another one with a high hippocampal volume ( $4448 \mathrm{~mm}^{3}$ ) and a high CoV of stride time (5.8\%) (b)) and a patient with $\mathrm{MCI}$ with a low hippocampal volume $\left(2751 \mathrm{~mm}^{3}\right)$ and a high $\mathrm{CoV}$ of stride time (4.9\%) (c). Multiple linear regression models showed that $\mathrm{CoV}$ of stride time was specifically associated with a higher hippocampal volume among $\mathrm{CHI}(\mathrm{P}=0.007$ for the absolute value and $\mathrm{P}=0.047$ for the ratio), but not among $\mathrm{MCl}$ individuals (Table 2). This association was not significant for absolute volume and ratio without adjustment (respectively, $\mathrm{P}=0.119$ and $\mathrm{P}=0.165$ in $\mathrm{CHI}$, and $\mathrm{P}=0.235$ and $\mathrm{P}=0.825$ in $\mathrm{MCI}$ ). No other association was reported between spatio-temporal gait parameters and hippocampal volume in both groups.

\section{Discussion}

This study revealed an unexpected positive association between a greater (i.e., better morphological structure) hippocampal volume and a greater (i.e., worse) STV among CHI, but not among patients with $\mathrm{MCI}$ in the studied sample of non-demented older community-dwellers.

Greater gait variability and lower hippocampal volume have been separately reported in patients with MCI (Fellgiebel \& Yakushev, 2011; Leal \& Yassa, 2013; Albert et al., 2011; Beauchet et al., 2009a, 2014; Montero-Odasso et al., 2012; Beauchet et al., 2013). Furthermore, a significant negative association between greater gait variability and lower hippocampal volume has been also shown in CHI (Albert et al., 2011; Dubois et al., 2014; Zimmerman et al., 2009; Shimada et al., 2013; Rosso et al., 2014; Annweiler et al., 2014). Thus, we hypothesized at first that higher gait variability would be stronger associated with lower hippocampal volume in patients with $\mathrm{MCl}$ individuals compared to $\mathrm{CHI}$. However, we did not find this excepted significant association between lower (i.e., worse) hippocampal volume and greater (i.e., worse) STV. The main explanation of this result could be related to the low level of STV observed in our sample of patients with MCI. Even if their mean value of $\mathrm{CoV}$ of stride time was higher than $\mathrm{CHI}$, it was still in the normal range (Beauchet et al., 2009a, 2014; Montero-Odasso et al., 2012). Indeed, STV previously reported in patients with $\mathrm{MCI}$ was already above $3 \%$, whereas in our study the mean CoV was 2.6\% (Beauchet et al., 2009a; Montero-Odasso et al., 2012; Beauchet et al., 2013). In contrast to these previous studies, we focused on a population of patients with $\mathrm{MCI}$ with very early cognitive decline that prevents us to observe the suggested association.

The positive association between a greater (i.e., better morphological structure) hippocampal volume and a greater (i.e., worse) STV in CHI highlights the role of the hippocampus in gait control during normal aging. Indeed, it was supported by a recent study that showed the effects of normal aging on the neural substrate of gait control using mental imagery during functional MRI of the brain: hippocampal regions in older adults presented an increased activation in comparison to younger ones in a task requiring a precise control of gait (i.e., walking on surface consisting of cobbles stones) (Allali et al., 2014). This additional hippocampal activation reflects the compensatory mechanism used to maintain a physiological control of gait. During normal aging, both higher and lower STV reflect efficient control of gait and safe gait (Beauchet et al., 2009a; Gabell \& Nayak, 1984). Lower STV reflects automatic walking process requiring low attention demands, whereas high STV is in relationship with high demanding walking task like walking on cobble stones (Woollacott \& Shumway-Cook, 2002). Our results are in line with the model suggesting that precise gait control requires hippocampal integrity in non-demented older adults. However, recent findings showed a morphological association between lower hippocampal integrity and higher stride length variability, this gait parameter being like STV a biomarker of the rhythmic stepping mechanism (Rosso et al., 2014). In addition, other studies focusing on brain metabolism also found an association between lower levels of hippocampal metabolism and higher stride length variability using proton magnetic 
Clinical, gait and hippocampal characteristics of participants according to their cognitive status $(\mathrm{n}=90)$.

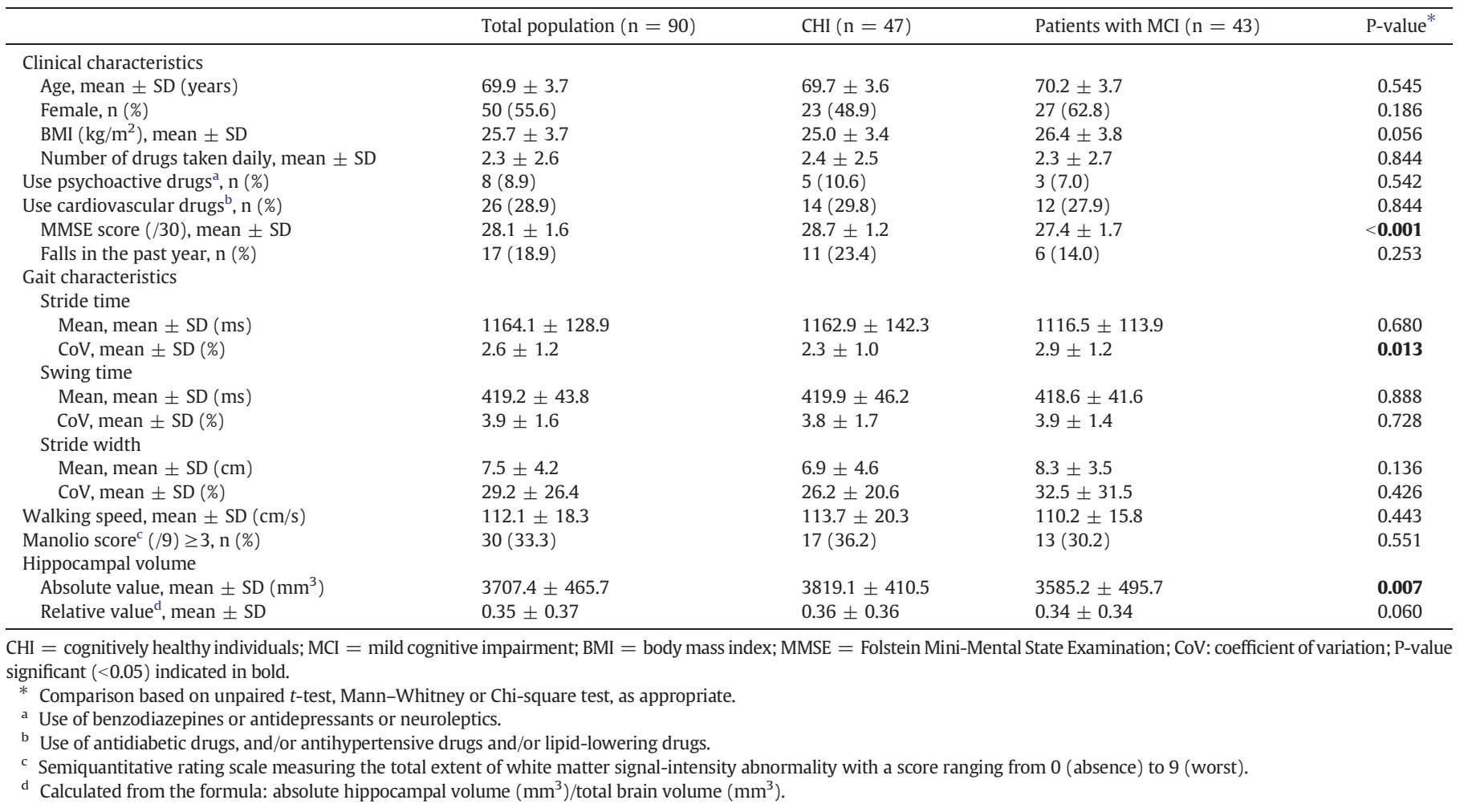

resonance spectroscopy or positron emission tomography (Zimmerman et al., 2009; Shimada et al., 2013). The fact that the current approach divided the study sample of non-demented older adults on a group of healthy aging and a group of participants with early signs of pathological aging (i.e., MCI) could explain these apparent divergences. So, this association between higher STV and higher hippocampal volume observed in the $\mathrm{CHI}$ group leads to the model of a specific role of the hippocampus in the control of gait, and more specifically in the control of the rhythmic stepping mechanism, during normal aging with an alternative role during pathological aging

Taken together the finding of a nonsignificant association between hippocampal volume and gait variability in patients with $\mathrm{MCI}$, but significant in $\mathrm{CHI}$, is in concordance with a recent study, which reported a tendency to a J-shaped change of the volume of ventricular bodies (an indirect marker of brain atrophy) according to the STV (categorized in tertiles), the lowest volume reported in the intermediate STV tertile (Annweiler et al., 2014). The presence of a compensatory mechanism in $\mathrm{CHI}$, could explain the significant positive association between greater (i.e., worse) STV and increased hippocampal volume among CHI that would be absent in $\mathrm{MCI}$ individuals due to the pathological process of $\mathrm{MCI}$. The capacity of focal cerebral plasticity has already been shown in response to environmental demands, especially in spatial navigation: learning the mental atlas of the streets in London, was associated with structural changes in the brain of licensed taxi drivers compared to controls, namely a greater volume of hippocampus (Maguire et al., 2000).

The univariate regression showing no association between $\mathrm{CoV}$ of stride time and hippocampal volume is hardly interpretable and has only little meaning as many factors contribute to gait variability. Thus, ignoring these covariables in a univariate model prevents valid conclusions (Annweiler et al., 2014; Beauchet et al., 2009a, 2014; Montero-Odasso et al., 2012; Beauchet et al., 2011, 2013; Kressig \& Beauchet, 2006). In contrast, the absence of significant association between mean values of studied spatio-temporal gait parameters while taking into account the effects of covariables is in concordance with previous studies that underscored that stride-to-stride variability, but not mean value, represents a biomarker of the highest (i.e., subcortical and cortical levels) levels of gait control (Beauchet et al., 2009a; Montero-Odasso et al., 2012; Beauchet et al., 2013). Furthermore, we did not show any association with stride-to-stride variability of swing time and stride width. In contrast to stride time, these two gait parameters are related to other components of gait control. Stride width is a marker of dynamic postural control and swing time reflects the dynamic postural control combined to the rhythmic stepping control (Beauchet et al., 2009a). Compared to STV, these two gait parameters are increased in individuals with safe gait (Beauchet et al., 2009a; Brach et al., 2005). From a biomechanical viewpoint, variability is necessary to maintain balance (Brach et al., 2005; Newell \& Corcos, 1993), which reflects the ability to adapt limb movement while walking, leading to greater stability (Beauchet et al., 2009a; Montero-Odasso et al., 2012; Beauchet et al., 2013; Brach et al., 2005; Newell \& Corcos, 1993). The higher variability of both these gait parameters compared to stride time or stride length is required to a maintain safe gait. Absence of association between swing time and stride width and hippocampal volume could be related to the fact that they both depend on others brain regions. Indeed, it has been shown that the age-related neural correlates for balance control are based on a specific network involving the parietal, frontal and the insular cortical areas in addition to the basal ganglia (Goble et al., 2011).

Although the strength of this study was designed to specifically identify healthy older adults from those with early signs of pathological aging in the relationship between hippocampal volume and gait control, this study is not without limitation. Due to the small number of patients with $\mathrm{MCI}$, a dichotomization of patients with $\mathrm{MCI}$ between the amnestic and non-amnestic subtypes was not possible because of a lack of power exposing to invalid results. While this study is the first to demonstrate an association between hippocampal volume and STV in physiological aging, the cross-sectional design does not afford causal inferences. Furthermore, using a longitudinal design, we would be able to determine whether changes in hippocampal volume precipitate higher STV in $\mathrm{CHI}$ and $\mathrm{MCI}$ patients, or whether worse gait performance precipitate 


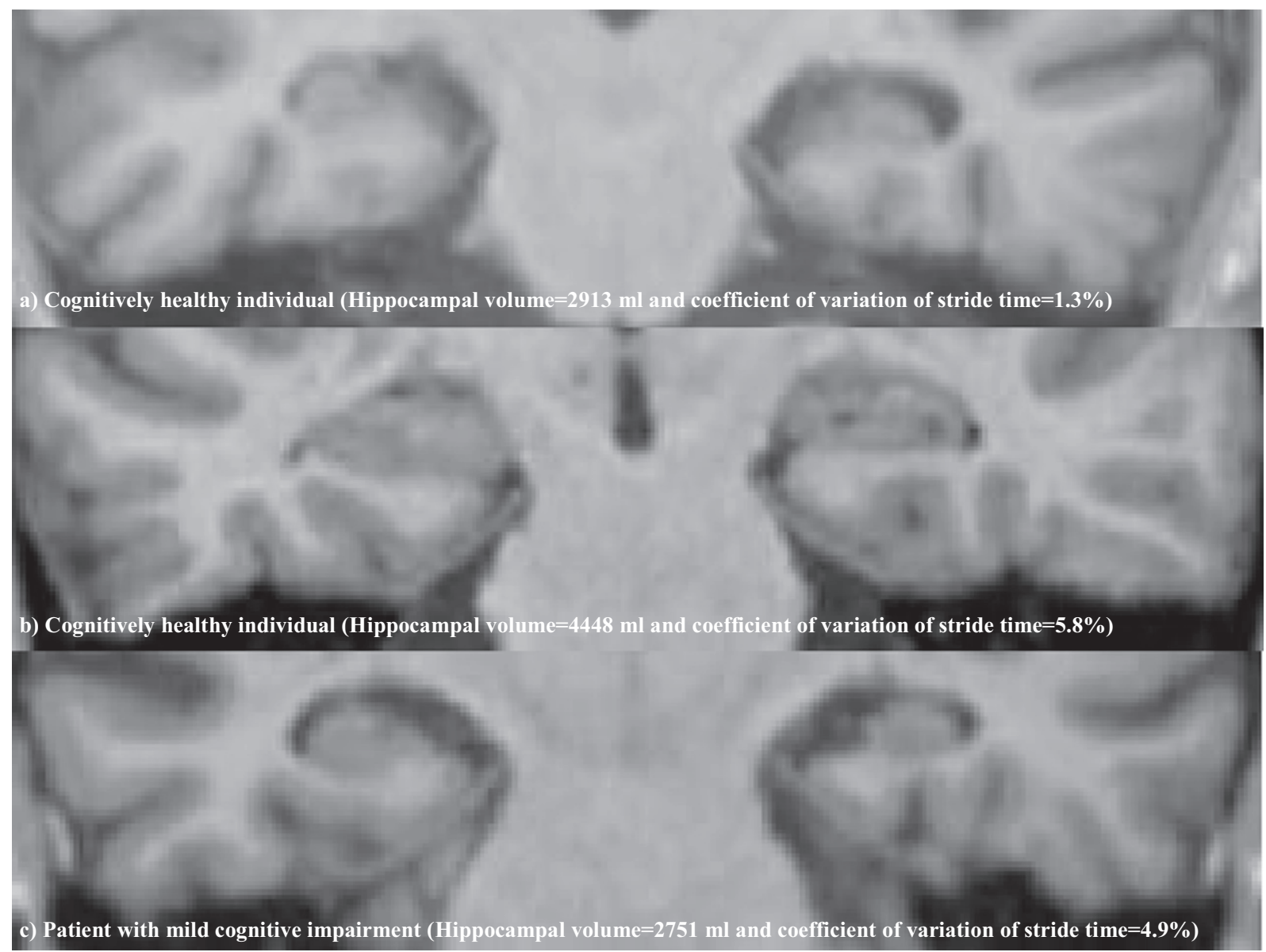

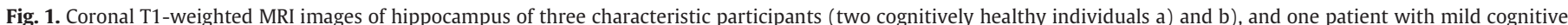
impairment c)).

changes in hippocampal morphology. Finally, the participants included in the GAIT study were referred to our center for the evaluation of a memory complaint. Thus, participants defined as $\mathrm{CHI}$ in our study presented the specificity of having a memory complaint, suggesting that the findings of the present study could be generalized to a pre-MCI population.
In conclusion, this study found a specific association between increased hippocampal volume and a greater STV in CHI, but not in patients with $\mathrm{MCI}$. These results suggest that the hippocampus may control the physiology of gait, specifically the rhythmic stepping mechanism, during normal aging, but not during pathological aging. Additional investigations are required to determine which brain regions

Table 2

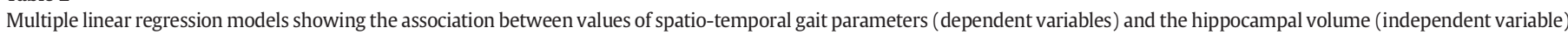
adjusted for clinical characteristics among participants separated on their cognitive status $(\mathrm{n}=90)$.

\begin{tabular}{|c|c|c|c|c|c|c|c|c|c|}
\hline & \multicolumn{3}{|l|}{ Stride time } & \multicolumn{3}{|l|}{ Swing time } & \multicolumn{3}{|l|}{ Stride width } \\
\hline & $ß$ & $95 \% \mathrm{CI}$ & P-value & $ß$ & $95 \% \mathrm{CI}$ & P-value & $\beta$ & $95 \% \mathrm{CI}$ & P-value \\
\hline \multicolumn{10}{|l|}{ a) Mean values } \\
\hline \multicolumn{10}{|l|}{$\mathrm{CHI}$} \\
\hline Absolute volume & 0.000 & {$[0.000 ; 0.000]$} & 0.451 & 0.000 & {$[0.000 ; 0.000]$} & 0.607 & 0.002 & {$[-0.002 ; 0.005]$} & 0.378 \\
\hline Relative volume ${ }^{*}$ & 15.8 & {$[-39.6 ; 71.3]$} & 0.567 & 4.8 & {$[-21.3 ; 30.9]$} & 0.711 & -1118.8 & {$[-5096.4 ; 2858.8]$} & 0.572 \\
\hline \multicolumn{10}{|l|}{$\mathrm{MCI}$} \\
\hline Absolute volume & 0.000 & {$[0.000 ; 0.000]$} & 0.252 & 0.000 & {$[0.000 ; 0.000]$} & 0.574 & 0.000 & {$[-0.002 ; 0.003]$} & 0.873 \\
\hline Relative volume & 23.5 & {$[-38.1 ; 85.0]$} & 0.443 & 2.0 & {$[-26.7 ; 30.7]$} & 0.808 & -368.1 & {$[-3048.2 ; 2312.0]$} & 0.782 \\
\hline \multicolumn{10}{|c|}{ b) Coefficients of variation } \\
\hline \multicolumn{10}{|c|}{$\mathrm{CHI}$} \\
\hline Absolute volume & 0.001 & {$[0.000 ; 0.002]$} & 0.007 & 0.000 & {$[-0.001 ; 0.001]$} & 0.882 & -0.007 & {$[-0.024 ; 0.010]$} & 0.407 \\
\hline Relative volume ${ }^{*}$ & 758.5 & {$[11.5 ; 1505.5]$} & 0.047 & 387.8 & {$[-1016.8 ; 1792.3]$} & 0.579 & -13572.1 & {$[-32119.1 ; 4974.9]$} & 0.147 \\
\hline \multicolumn{10}{|l|}{$\mathrm{MCI}$} \\
\hline Absolute volume & 0.000 & {$[-0.001 ; 0.001]$} & 0.667 & -0.001 & {$[-0.002 ; 0.000]$} & 0.142 & 0.017 & {$[-0.011 ; 0.044]$} & 0.223 \\
\hline Relative volume ${ }^{*}$ & -133.2 & {$[-1148.9 ; 882.5]$} & 0.791 & -604.5 & {$[-1638.1 ; 429.1]$} & 0.243 & 22130.3 & {$[-5156.5 ; 49417.2]$} & 0.108 \\
\hline
\end{tabular}

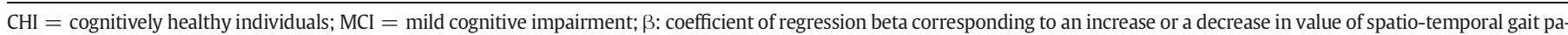

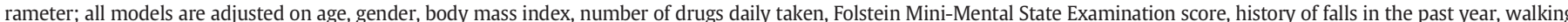

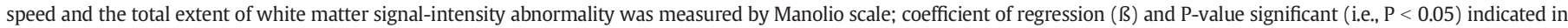
bold.

* Calculated from the formula: absolute hippocampal volume/total brain volume. 
are involved in the pathophysiological mechanisms of the stepping mechanisms contributing to the higher gait variability found in the different forms of pathological aging.

\section{Acknowledgments}

The authors have listed everyone who contributed significantly to the work in the Acknowledgments section. Permission has been obtained from all persons named in the Acknowledgments section.

- Melinda Beaudenon, MSc, Jennifer Gautier, BS, Romain Simon, MS, and Samuel Thiery, BS, from Angers University Memory Clinic, France, for daily assistance. There was no compensation for this contribution.

- Jean-Yves Tanguy, MD, Anne Pasco-Papon, MD, PhD, Christophe Aube $\mathrm{MD}, \mathrm{PhD}$, from the Department of Radiology, Angers University Hospital, France, for technical support. There was no compensation for this contribution.

\section{Conflict of interest}

\section{- Disclosures:}

- CA: serves as an unpaid associate editor for Gériatrie, Psychologie et Neuropsychiatrie du Vieillissement and for the Journal of Alzheimer's Disease. He has no relevant financial interest in this manuscript.

- OB: serves as an unpaid associate editor for Gériatrie, Psychologie et Neuropsychiatrie du Vieillissement. He has no relevant financial interest in this manuscript.

- GA: serves as an unpaid associate editor for Scientific World Journal. He has no relevant financial interest in this manuscript.

\section{- Funding}

- The study was financially supported by the French Ministry of Health (Projet Hospitalier de Recherche Clinique national $n^{\circ}$ 2009-A00533-54).

- Gilles Allali is funded by a grant from the Geneva University Hospitals.

- Software for quantification of brain ventricle volumes was provided my Merge Healthcare (Mississauga, Canada).

- The sponsors had no role in the design and conduct of the study, in the collection, management, analysis, and interpretation of the data, or in the preparation, review, or approval of the manuscript

\section{Author contributions}

- OB has full access to all of the data in the study, takes responsibility for the data, the analyses and interpretation and has the right to publish any and all data, separate and apart from the attitudes of the sponsor.

- Study concept and design: OB, CA and GA.

- Acquisition of data: $\mathrm{OB}$ and $\mathrm{CA}$.

- Analysis and interpretation of data: OB and GA.

- Drafting of the manuscript: OB and GA.

- Critical revision of the manuscript for important intellectual content: CPL and CA.

- Obtained funding: $\mathrm{OB}$.

- Statistical expertise: $\mathrm{OB}$.

- Administrative, technical, or material support: CA and OB.

- Study supervision: GA.

\section{References}

Albert, M.S., DeKosky, S.T., Dickson, D., Dubois, B., Feldman, H.H., Fox, N.C., Gamst, A Holtzman, D.M., Jagust, W.J., Petersen, R.C., Snyder, P.J., Carrillo, M.C., Thies, B. Phelps, C.H., 2011. The diagnosis of mild cognitive impairment due to Alzheimer's disease: recommendations from the National Institute on Aging-Alzheimer's Association workgroups on diagnostic guidelines for Alzheimer's disease. Alzheimer's Dement. 7, 270-279.

Allali, G., van der Meulen, M., Beauchet, O., Rieger, S.W., Vuilleumier, P., Assal, F., 2014. The neural basis of age-related changes in motor imagery of gait: an fMRI study. J. Gerontol. A Biol. Sci. Med. Sci. 69, 1389-1398.

Annweiler, C., Montero-Odasso, M., Bartha, R., Drozd, J., Hachinski, V., Beauchet, O., 2014 Association between gait variability and brain ventricle attributes: a brain mapping study. Exp. Gerontol. 57C, 256-263.
Beauchet, O., Allali, G., Annweiler, C., Bridenbaugh, S., Assal, F., Kressig, R.W., Herrmann, F.R., 2009a. Gait variability among healthy adults: low and high stride-to-stride variability are both a reflection of gait stability. Gerontology 55, 702-706.

Beauchet, O., Annweiler, C., Lecordroch, Y., Allali, G., Dubost, V., Herrmann, F.R., Kressig, R.W., Aug 5 2009b. Walking speed-related changes in stride time variability: effects of decreased speed. J. Neuroeng. Rehabil. 6, 32.

Beauchet, O., Freiberger, E., Annweiler, C., Kressig, R.W., Herrmann, F.R., Allali, G., 2011. Test-retest reliability of stride time variability while dual tasking in healthy and demented adults with frontotemporal degeneration. J. Neuroeng. Rehabil. 8, 37.

Beauchet, O., Allali, G., Launay, C., Herrmann, F.R., Annweiler, C., 2013. Gait variability at fast-pace walking speed: a biomarker of mild cognitive impairment? J. Nutr. Health Aging 17, 235-239.

Beauchet, O., Allali, G., Montero-Odasso, M., Sejdić, E., Fantino, B., Annweiler, C., 2014. Motor phenotype of decline in cognitive performance among community-dwellers without dementia: population-based study and meta-analysis. PLoS One 9, e99318.

Brach, J.S., Berlin, J.E., VanSwearingen, J.M., Newman, A.B., Studenski, S.A., 2005. Too much or too little step width variability is associated with a fall history in older persons who walk at or near normal gait speed. J. Neuroeng. Rehabil. 2, 21.

Brown, E.C., Casey, A., Fisch, R.I., Neuringer, C., 1958. Trail making test as a screening device for the detection of brain damage. J. Consult. Psychol. 22, 469-474.

Dale, A.M., Fischl, B., Sereno, M.I., 1999. Cortical surface-based analysis. I. Segmentation and surface reconstruction. Neuroimage 9, 179-194.

Desikan, R.S., Segonne, F., Fischl, B., Quinn, B.T., Dickerson, B.C., Blacker, D., Buckner, R.L., Dale, A.M., Maguire, R.P., Hyman, B.T., Albert, M.S., Killiany, R.J., 2006. An automated labeling system for subdividing the human cerebral cortex on MRI scans into gyral based regions of interest. Neuroimage 31, 968-980.

Dubois, B., Slachevsky, A., Litvan, I., Pillon, B., 2000. The FAB: a Frontal Assessment Battery at bedside. Neurology 55, 1621-1626.

Dubois, B., Sarazin, M., Lehericy, S., et al., 2009. P2a-4 etude hippocampe: evaluation de l'efficacité du donépézil versus placebo sur des marqueurs IRM et cliniques chez des patients présentant des troubles cognitifs légers. Rev. Neurol. 165, 66-67.

Dubois, B., Feldman, H.H., Jacova, C., Cummings, J.L., Dekosky, S.T., Barberger-Gateau, P., Delacourte, A., Frisoni, G., Fox, N.C., Galasko, D., Gauthier, S., Hampel, H., Jicha, G.A., Meguro, K., O'Brien, J., Pasquier, F., Robert, P., Rossor, M., Salloway, S., Sarazin, M., de Souza, L.C., Stern, Y., Visser, P.J., Scheltens, P., 2010. Revising the definition of Alzheimer's disease: a new lexicon. Lancet Neurol. 9, 1118-1127.

Dubois, B., Feldman, H.H., Jacova, C., Hampel, H., Molinuevo, J.L., Blennow, K., DeKosky, S.T., Gauthier, S., Selkoe, D., Bateman, R., Cappa, S., Crutch, S., Engelborghs, S., Frisoni, G.B., Fox, N.C., Galasko, D., Habert, M.O., Jicha, G.A., Nordberg, A., Pasquier, F., Rabinovici, G., Robert, P., Rowe, C., Salloway, S., Sarazin, M., Epelbaum, S., de Souza, L.C., Vellas, B., Visser, P.J., Schneider, L., Stern, Y., Scheltens, P., Cummings, J.L., 2014. Advancing research diagnostic criteria for Alzheimer's disease: the IWG-2 criteria. Lancet Neurol. 13, 614-629.

Fellgiebel, A., Yakushev, I., 2011. Diffusion tensor imaging of the hippocampus in $\mathrm{MCI}$ and early Alzheimer's disease. J. Alzheimer's Dis. 26 (Suppl. 3), 257-262.

Fischl, B., Sereno, M.I., Dale, A.M., 1999a. Cortical surface-based analysis. II: inflation, flattening, and a surface-based coordinate system. Neuroimage 9, 195-207.

Fischl, B., Sereno, M.I., Tootell, R.B., Dale, A.M., 1999b. High-resolution intersubject averaging and a coordinate system for the cortical surface. Hum. Brain Mapp. 8, 272-284.

Fischl, B., Liu, A., Dale, A.M., 2001. Automated manifold surgery: constructing geometrically accurate and topologically correct models of the human cerebral cortex. IEEE Trans. Med. Imaging 20, 70-80.

Fischl, B., Salat, D.H., Busa, E., Albert, M., Dieterich, M., Haselgrove, C., van der Kouwe, A., Killiany, R., Kennedy, D., Klaveness, S., Montillo, A., Makris, N., Rosen, B., Dale, A.M., 2002. Whole brain segmentation: automated labeling of neuroanatomical structures in the human brain. Neuron 33, 341-355.

Fischl, B., Salat, D.H., van der Kouwe, A.J., Makris, N., Segonne, F., Quinn, B.T., Dale, A.M., 2004. Sequence-independent segmentation of magnetic resonance images. Neuroimage 23, S69-S84.

Folstein, M.F., Folstein, S.E., McHugh, P.R., 1975. "Mini-mental state". A practical method for grading the cognitive state of patients for the clinician. J. Psychiatr. Res. 12, 189-198.

Gabell, A., Nayak, U.S., 1984. The effect of age on variability in gait. J. Gerontol. 39, 662-666.

Goble, D.J., Coxon, J.P., Van Impe, A., Geurts, M., Doumas, M., Wenderoth, N., Swinnen, S.P., 2011. Brain activity during ankle proprioceptive stimulation predicts balance performance in young and older adults. J. Neurosci. 31, 16344-16352.

Grober, E., Buschke, H., Crystal, H., Bang, S., Dresner, R., 1988. Screening for dementia by memory testing. Neurology 38, 900-903.

Han, X., Jovicich, J., Salat, D., van der Kouwe, A., Quinn, B., Czanner, S., Busa, E., Pacheco, J., Albert, M., Killiany, R., Maguire, P., Rosas, D., Makris, N., Dale, A., Dickerson, B., Fischl, B., 2006. Reliability of MRI-derived measurements of human cerebral cortical thickness: the effects of field strength, scanner upgrade and manufacturer. Neuroimage 32, 180-194.

Jovicich, J., Czanner, S., Greve, D., Haley, E., van der Kouwe, A., Gollub, R., et al., 2006. Reliability in multi-site structural MRI studies: effects of gradient non-linearity correction on phantom and human data. Neuroimage 30, 436-443.

Kapeller, P., Barber, R., Vermeulen, R.J., et al., 2003. Visual rating of age-related white matter changes on magnetic resonance imaging: scale comparison, interrater agreement, and correlations with quantitative measurements. Stroke 34, 441-445.

Kressig, R.W., Beauchet, O., 2006. Guidelines for clinical applications of spatio-temporal gait analysis in older adults. Aging Clin. Exp. Res. 18, 174-176.

Kuperberg, G.R., Broome, M.R., McGuire, P.K., David, A.S., Eddy, M., Ozawa, F., et al., 2003. Regionally localized thinning of the cerebral cortex in schizophrenia. Arch. Gen. Psychiatry 60, 878-888.

Leal, S.L., Yassa, M.A., 2013. Perturbations of neural circuitry in aging, mild cognitive impairment, and Alzheimer's disease. Ageing Res. Rev. 12, 823-831. 
Lithfous, S., Dufour, A., Després, O., 2013. Spatial navigation in normal aging and the prodromal stage of Alzheimer's disease: insights from imaging and behavioral studies. Ageing Res. Rev. 12, 201-213.

Maguire, E.A., Gadian, D.G., Johnsrude, I.S., Good, C.D., Ashburner, J., Frackowiak, R.S., Frith, C.D., 2000. Navigation-related structural change in the hippocampi of taxi drivers. Proc. Natl. Acad. Sci. U. S. A. 97, 4398-4403.

Manolio, T.A., Kronmal, R.A., Burke, G.L., et al., 1994. Magnetic resonance abnormalities and cardiovascular disease in older adults: the Cardiovascular Health Study. Stroke $25,318-327$.

Montero-Odasso, M., Verghese, J., Beauchet, O., Hausdorff, J.M., 2012. Gait and cognition: a complementary approach to understanding brain function and the risk of falling. J. Am. Geriatr. Soc. 60, 2127-2136.

Newell, K.M., Corcos, D.M., 1993. Issues in variability and motor control. In: Newell, K.M., Corcos, D.M. (Eds.), Variability and Motor Control. Human Kinetics, Champaign, pp. $1-12$.

Pérès, K., Chrysostome, V., Fabrigoule, C., Orgogozo, J.M., Dartigues, J.F., Barberger-Gateau, P., 2006. Restriction in complex activities of daily living in MCI: impact on outcome. Neurology 67, 461-466.

Rosano, C., Brach, J., Studenski, S., Longstreth Jr., W.T., Newman, A.B., 2007. Gait variability is associated with subclinical brain vascular abnormalities in high-functioning older adults. Neuroepidemiology 29, 193-200.

Rosas, H.D., Liu, A.K., Hersch, S., Glessner, M., Ferrante, R.J., Salat, D.H., van der Kouwe, A. Jenkins, B.G., Dale, A.M., Fischl, B., 2002. Regional and progressive thinning of the cortical ribbon in Huntington's disease. Neurology 58, 695-701.

Rosen, W.G., Mohs, R.C., Davis, K.L., 1984. A new rating scale for Alzheimer's disease. Am. J. Psychiatry 141, 1356-1364.

Rosso, A.L., Olson Hunt, M.J., Yang, M., Brach, J.S., Harris, T.B., Newman, A.B., Satterfield, S., Studenski, S.A., Yaffe, K., Aizenstein, H.J., Rosano, C., 2014. Health ABC study. Higher step length variability indicates lower gray matter integrity of selected regions in older adults. Gait Posture 40, 225-230.

Scherder, E., Eggermont, L., Swaab, D., van Heuvelen, M., Kamsma, Y., de Greef, M., van Wijck, R., Mulder, T., 2007. Gait in ageing and associated dementias; its relationship with cognition. Neurosci. Biobehav. Rev. 31, 485-497.

Segonne, F., Dale, A.M., Busa, E., Glessner, M., Salat, D., Hahn, H.K., Fischl, B., 2004. A hybrid approach to the skull stripping problem in MRI. Neuroimage 22, 1060-1075.

Seidler, R.D., Bernard, J.A., Burutolu, T.B., Fling, B.W., Gordon, M.T., Gwin, J.T., Kwak, Y Lipps, D.B., 2010. Motor control and aging: links to age-related brain structural, functional, and biochemical effects. Neurosci. Biobehav. Rev. 34, 721-733.

Shah, A., Herbert, R., Lewis, S., Mahendran, R., Platt, J., Bhattacharyya, B., 1997. Screening for depression among acutely ill geriatric in patients with a short Geriatric Depression Scale. Age Ageing 26, 217-221.

Shimada, H., Ishii, K., Ishiwata, K., Oda, K., Suzukawa, M., Makizako, H., Doi, T., Suzuki, T., 2013. Gait adaptability and brain activity during unaccustomed treadmill walking in healthy elderly females. Gait Posture 38, 203-208.

Van der Linden, M., Coyette, F., Poitrenaud, F., Kalafat, M., Calicis, F., Adam, F., 2004. L'épreuve de rappel libre/rappel indicé à 16 items (RL/RI-16). In: Solal (Ed.), L'évaluation des troubles de la mémoire. Solal, Marseille.

Woollacott, M., Shumway-Cook, A., 2002. Attention and the control of posture and gait: a review of an emerging area of research. Gait Posture 16, 1-14.

Zimmerman, M.E., Lipton, R.B., Pan, J.W., Hetherington, H.P., Verghese, J., 2009. MRI- and MRS-derived hippocampal correlates of quantitative locomotor function in older adults. Brain Res. 1291, 73-81. 